\title{
Causal Factors and Management Options of Infertility in Kuwait
}

\author{
A.E. Omu F. Al-Qattan A.A. Ismail S.I. Al-Taher N. Al-Busiri \\ A. Bandar \\ Department of Obstetrics and Gynaecology, Faculty of Medicine, Kuwait University and \\ Maternity Hospital, Kuwait
}

\section{Key Words}

Determinants · Infertility $\cdot$ Couple .

Treatment $\cdot$ Options

\begin{abstract}
Objective: To determine the main causes and management options of infertility in Kuwait. Methodology: Clinical evaluation, hormone profile of $\mathrm{LH}, \mathrm{FSH}$, prolactin and testosterone and midluteal phase progesterone, tubal patency tests, semen analysis and antisperm antibodies were assessed. Treatment included medical and surgical induction of ovulation. Male factor infertility was treated with antibiotics and immunosuppression when indicated, and empirically with antioxidants. Results: The main cause of female infertility was ovarian dysfunction (40.7\%) with predominance of polycystic ovarian syndrome (52.9\%), anovulatory regular cycles $(25 \%)$ and hyperprolactinaemia (14.3\%). Male factor accounted for infertility in $40.2 \%$ of the couples, with asthenozoospermia in $34.3 \%$, oligozoospermia in $29.2 \%$ and azoo-
\end{abstract}

\begin{tabular}{ll}
\hline KARGER & ( ) 2000 S. Karger AG, Basel \\
$1011-7571 / 00 / 0092-0131 \$ 17.50 / 0$ \\
Fax +4161306 1234 & \\
$\begin{array}{l}\text { E-Mail karger@karger.ch } \\
\text { www.karger.com }\end{array}$ & $\begin{array}{l}\text { Accessible online at: } \\
\text { www.karger.com/journals/mpp }\end{array}$
\end{tabular}

spermia in $8.2 \%$. Immuological tubal factors and endometriosis occurred in 9.8, 5.9 and $5.6 \%$, respectively, and unexplained infertility in $8.5 \%$. Both spouses were involved in $36.5 \%$ of the couples. Clomiphene citrate was the commonest agent for induction of ovulation with an $80 \%$ success rate. Bromocriptine, gonadotropins and laparoscopic ovarian cautery had success rates of 71, 69, and $80 \%$, respectively. Treatment outcome in male factor infertility was variable. Conclusion: Ovarian dysfunction and male factor infertility are the dominant factors responsible for infertility in Kuwait. Induction of ovulation has a good prognosis of $40-80 \%$ success rate. Tubal factor infertility is uncommon in Kuwait.

$$
\text { Copyright } @ 2000 \text { S. Karger AG, Basel }
$$

\section{Introduction}

The current epidemiological evidence suggests that $15 \%$ of the couples will experience infertility and in half this number, the prob-

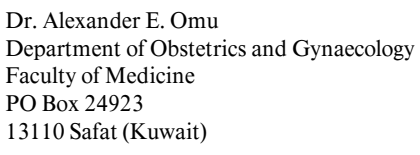


lem will remain unsolved [1] without the use of assisted reproductive technology. A knowledge of the epidemiology of infertility is important when taking the couple's history, especially at the initial visit when a comprehensive medical and surgical history of both partners should be obtained to help direct the infertility evaluation. Fertility is affected by many different cultural, environmental and socioeconomic factors. The proportion of women in the US aged 15-44 years who reported some form of fecundity impairment rose from $8 \%$ in 1982 and 1988 to $10 \%$ in 1995, an increase in absolute numbers from 4.6 million to 6.5 million women. This dramatic increase is thought to have occurred because of the large baby boom cohort, many of whom delayed childbearing, had reached their later and less fecund reproductive years [2]. In a recent study, a measure of infertility was used that provided for reliable estimates of national prevalence rates in 27 African nations. The results indicate considerable variation in infertility of rates between nations across the continnent of Africa. Whatever the national rate, within each nation infertility is strongly associated with social, behavioural and cultural factors that are known to put women at risk for sexually transmitted diseases and other reproductive tract infections most closely associated with clinical infertility [3]. Since environmental factors play a major role in infertility in Africa, where infections are commonplace, the most costeffective approach to solving the infertility problem in Africa is therefore prevention and education. In Mexico, problems of reproductive health are associated with pregnancy in adolescents, sexually transmitted diseases and genitourinary neoplasm like carcinoma of cervix in women and of testis in men. Education, poverty, nutrition and pollution are problems that must be tackled [4]. In a study from China, the overall infertility rate was $5.0 \%$. A sig- nificantly higher rate was found for couples whose husbands were engaged in cotton farming, and also among smokers [5]. In a study from Western Australia surgical sterility accounted for $37.1 \%$ [6]. Understanding the reasons for infertility and the development of new techniques for its treatment is one of the fields within medicine which has undergone a dramatic development during the last two decades [7].

The main objective of this study is to evaluate the determinants and treatment options for infertility in the first 600 consecutive patients in a combined infertility clinic in $\mathrm{Ku}-$ wait.

\section{Patients and Methods}

Patients in this report include consecutive women and their husbands who attended the infertility clinic from September 1994 to August 1998, with inability to achieve conception of at least 12 months' duration. The evaluation protocol included menstrual, pregnancy, contraceptive and sexual history, childhood illness like mumps-orchitis and trauma to the testis. Social habits like cigarette smoking and alcohol consumption were noted. On physical examination, hirsutism, weight and height were documented for computing the body mass index (BMI). Laboratory evaluation protocol included semen analysis according to WHO guidelines, antisperm antibodies with an immunofluorescence technique. The sperm parameters were defined on the basis of their spermatozoal concentration, motility and morphology: (a) normozoospermia, that is sperm count $20 \times 10^{6} / \mathrm{ml}$ or more; (b) normal motility is when $60 \%$ or more of the sperms in the sample are motile; (c) normal morphology means more than $60 \%$ of the sperm have normal morphology; (d) oligozoospermia is when the sperm count is less than $20 \times 10^{6 /}$ $\mathrm{ml}$ of semen; (e) azoospermia, no spermatozoa in the semen even after centrifugation; (f) asthenozoospermia, more than $40 \%$ of the sperm are non-motile.

Semen culture and leukocytospermia estimation were carried out in men with high seminal levels of white blood cells. Leukocytospermia was present if leukocytes in semen were up to $1 \times 10^{6} / \mathrm{ml}$ or more. Hormone profile involving luteinising hormone (LH), follicle-stimulating hormone (FSH), prolactin, testosterone, thyroid function tests and midluteal phase serum
132

Med Principles Pract 2000;9:131-138
Omu/Al-Qattan/Ismail/Al-Taher/ Al-Busiri/Bandar 
Table 1. Characteristics of patients

\begin{tabular}{|c|c|c|c|}
\hline & Female & \multicolumn{2}{|c|}{ Male } \\
\hline Age, years ${ }^{1}$ & $29.9 \pm 5.4(18-45)$ & 35. & $1(22-62)$ \\
\hline Menarche, years ${ }^{1}$ & $12.9 \pm 1.3(8-17)$ & - & \\
\hline Parity, years ${ }^{1}$ & $0.9 \pm 0.8$ & - & \\
\hline Primary infertility & $378 \quad(63 \%)$ & 385 & $(64 \%)$ \\
\hline Secondary infertility & $(37 \%)$ & 215 & $(36 \%)$ \\
\hline \multicolumn{4}{|l|}{ Nationality } \\
\hline Kuwaitis & $(56.5 \%)$ & 344 & $(57.3 \%)$ \\
\hline Non-Kuwaitis & $(43.5 \%)$ & 256 & $(42.7 \%)$ \\
\hline Duration of infertility, years ${ }^{1}$ & $5.3 \pm 4.0 \quad(1-20)$ & & $7(1-29)$ \\
\hline Smokers & $57 \quad(9.5 \%)$ & 256 & $(42.7 \%)$ \\
\hline
\end{tabular}

progesterone was done. All men with persistent azoospermia after three consecutive semen analyses and thorough centrifugation without sperm being detected had a fine needle testicular aspiration biopsy. All patients over 35 years or patients who had been married for 5 years or more had tubal evaluation with hysterosalpingography or diagnostic laparoscopy and hysteroscopy and a dye test for tubal, peritoneal and uterine factors.

Interventional strategies included medical and surgical induction of ovulation. As demonstrated in the present study, clomiphene citrate remains the first line of therapy for ovulation induction in infertile patients with polycystic ovaries. We have used ascending doses of clomiphene citrate; 166 patients received 50, 100, 150 , or $200 \mathrm{mg}$ daily for 5 days from the 2 nd day of the menstrual or withdrawal bleeding. The $200 \mathrm{mg}$ of clomiphene citrate was only given to the cohort of 32 women who failed to respond to the $150-\mathrm{mg}$ dose and showed no evidence of follicular growth on ultrasonography. None of the patients had manifestations of ovarian hyperstimulation. Twenty-four patients with anovulation as a result of hyperprolactinaemia had bromocriptine $2.5,5.0$ or $7.5 \mathrm{mg}$ daily for 3-6 months. Sixty-seven patients with clomiphene citrate resistance initially had a combination of $100 \mathrm{mg}$ of clomiphene citrate and $2.5 \mathrm{mg}$ of bromocriptine, while the remaining 13 were administered gonadotropins (FSH) and human chorionic gonadotropin (HCG). Patients with resistance to clomiphene citrate and gonadotropins had laparoscopic ovarian cautery. The outcome of induction of ovulation was monitored with ultrasonographic folliculometry and midluteal phase serum progesterone, and the presence of a corpus luteum at lapa- roscopy confirmed ovulation. Adhesiolysis was done for some patients in the presence of pelvic adhesions at laparoscopy. Men with significant circulating antisperm antibodies were treated with immunosuppression with prednisolone $5 \mathrm{mg}$ daily for 3-6 months, while those with confirmed seminal infection after seminal culture had appropriate antibiotics. For men with oligo-asthenozoospermia, antioxidants in the form of zinc and vitamins A, C, and E were administered for 3-6 months. All men with obstructive azoospermia and couples who did not achieve conception after 1 year of this conservative management were advised assisted reproduction technology, and subsequently referred to the IVF Centre of the hospital.

\section{Statistical Analysis}

Data were computerised and analysed by SPSS with windows and percentage occurrence calculated. Patients' characteristics were expressed as mean \pm standard deviation and hormones as median values.

\section{Results}

The patients' characteristics are shown in table 1 . Men were generally older than the women $(p<0.05)$. Sixty women $(10 \%)$ were aged $40-45$ years. On the whole, $378(63 \%)$ of the women had primary infertility. The oldest man, who came with the third wife, was 62 years old. While $42.7 \%$ of the men admitted to smoking, only $9.5 \%$ of the women were 
Fig. 1. Causal factors of infertility.

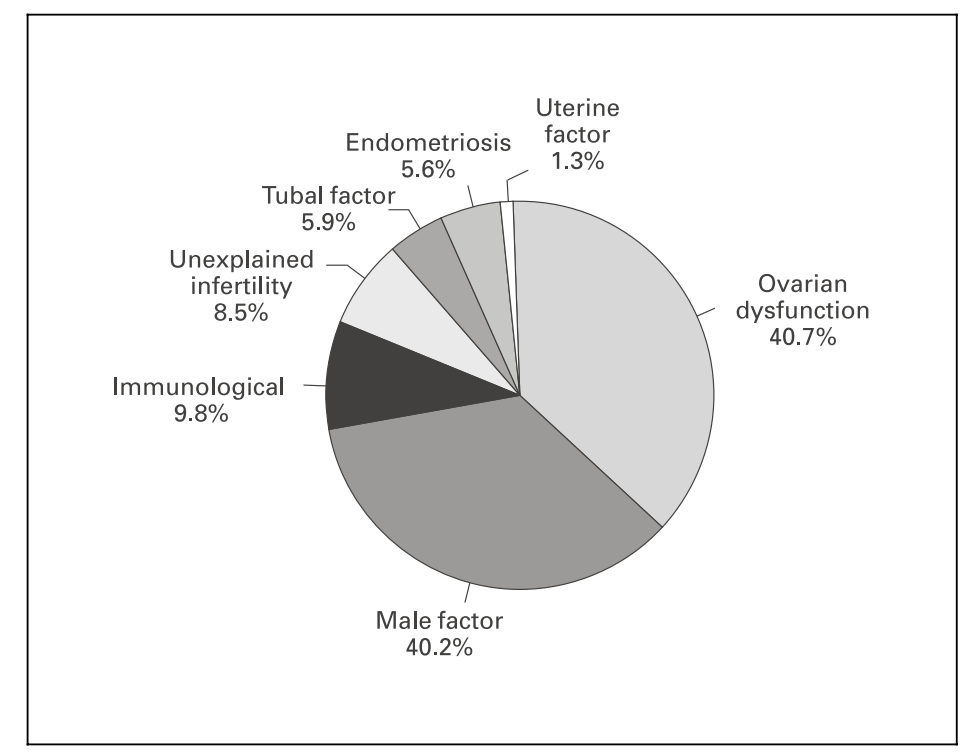

Table 2. Ovarian dysfunction

\begin{tabular}{lrc}
\hline & \multicolumn{2}{c}{$\begin{array}{l}\text { Women } \\
(\mathrm{n}=244)\end{array}$} \\
\cline { 2 - 3 } & $\mathrm{n}$ & $\%$ \\
\hline Polycystic ovary $^{1}$ & 129 & 52.9 \\
Hirsutism $^{1}$ & 52 & 40.3 \\
Hypergonadotropic hypogonadism & 5 & 2.0 \\
Hyperprolactinaemia & 35 & 14.3 \\
Hypothyroidism & 10 & 4.1 \\
Luteinised unruptured follicles & 2 & 0.08 \\
Cushing's syndrome & 3 & 1.2 \\
Anovulatory regular cycles & 61 & 25.0 \\
\hline
\end{tabular}

1 Hirsutism is a male hair distribution pattern in the woman.

smokers. As shown in figure 1, 244 (40.7\%) of the women had hypothalamic-pituitary-ovarian-endometrial axis dysfunction with anovulation, making it the commonest single factor causing infertility among the patients. A male factor was present in 241 out of the 600 men
(40.2\%), with $9.8 \%$ of the men having antisperm antibodies. Female tubal factors were comparatively uncommon in 5.9\%. Endometriosis (peritoneal factor) occurred in 34 patients (5.6\%). In 52 patients (8.5\%), no abnormality could be detected in either spouse with the methods of patients evaluation used (unexplained infertility). Although there were no details of psychological factor evaluation, in 7 couples $(1.2 \%)$ there was a problem of nonconsummation of the marriage of 1.3-5 years' duration. Impotence was present in 11 patients $(1.8 \%)$ and premature ejaculation in 9 patients $(1.5 \%)$. As shown in table 2 , polycystic ovarian syndrome (52.9\%) was the commonest endocrinopathy. The diagnostic characteristics of such women included menstrual abnormalities like oligomenorrhoea or amenorrhoea, anovulatory infertility, and obseity, with high circulating LH and hirsutism. Ultrasonographic or laparoscopic appearance of enlarged ovaries with multiple cysts without stigmata of ovulation added more weight to the diagnosis. Sixty-one women $(25 \%)$ of the 
Table 3. Hormone profiles for both spouses

\begin{tabular}{|c|c|c|c|c|}
\hline & \multicolumn{2}{|l|}{ Male } & \multicolumn{2}{|l|}{ Female } \\
\hline & median & $\begin{array}{l}\text { normal values } \\
\text { for clinic men }\end{array}$ & median & $\begin{array}{l}\text { normal values } \\
\text { for clinic women }\end{array}$ \\
\hline LH, IU/1 & 5.2 & $2.2-12$ & 6.2 & $2-15.4$ \\
\hline FSH, IU/1 & 6.8 & $0.9-9.8$ & 6.4 & $2.5-9.0$ \\
\hline Prolactin, mIU/l & 330 & $60-380$ & 342 & $71-424$ \\
\hline Testosterone, $\mathrm{nmol} / \mathrm{l}$ & 17.8 & $10.5-35$ & 1.8 & $0.7-2.3$ \\
\hline SHBG, nmol/1 & 19.6 & 11-71 & 48 & $20-118$ \\
\hline $\mathrm{FT}_{4}, \mathrm{pmol} / \mathrm{l}$ & 17.8 & $11-24$ & 18 & $11.0-24$ \\
\hline $\mathrm{FT}_{3}, \mathrm{pmol} / \mathrm{l}$ & 4.9 & $3.3-72$ & 4.6 & $2.4-7.2$ \\
\hline Progesterone, $\mathrm{nmol} / \mathrm{l}$ & - & - & 36 & $9.5-100$ \\
\hline
\end{tabular}

High LH and FSH in the male occurred in secretory azoospermiae, especially Sertoli's cells only. SHBG = Sex hormone binding globulin; $\mathrm{FT}_{4}=$ free thyroxine; $\mathrm{FT}_{3}=$ free tri-iodothyronine.

244 women with anovulation had regular menstrual cycles. Fifty-two (40.3\%) out of 129 patients with polycystic ovaries had hirsutism; 105 (81.4\%) had body mass index of more than 26 , and $81(62.8 \%)$ more than 30 . Five to ten percent of these women had abnormal levels of $\mathrm{LH}, \mathrm{FSH}$, prolactin, testosterone, respectively, and $40.7 \%$ had low levels of progesterone (table 3). Four hundred and thirty-four women had hysterosalpingogram and laparoscopy; 11 and $18 \%$ of the patients, respectively, had bilateral tubal block and $10 \%$ had a peritoneal factor in the form of endometriosis. Eight patients had uterine synechiae and 11 had a submucous fibroid confirmed by hysteroscopy.

In table 4, the male factor is evaluated. Sixty-two percent of the men had normozoospermia. Four men $(0.7 \%)$ had polyzoospermia that is more than 250 million spermatozoa per millilitre of semen. Oligozoospermia occurred in $29.2 \%$ of the men, of which $61 \%$ was severe and in the remaining 39\% it was mild. Forty-nine men $(8.2 \%)$ had azoospermia; of
Table 4. Male for factor evaluation: spermatozoal parameters

\begin{tabular}{lrc}
\hline & \multicolumn{2}{l}{ Patients } \\
\cline { 2 - 3 } & $\mathrm{n}$ & $\%$ \\
\hline Sperm count & & \\
Normozoospermia & 372 & 62 \\
Oligozoospermia & 175 & 29.2 \\
Azoospermia & 49 & 8.2 \\
Polyzoospermia & 4 & 0.7 \\
\hline Sperm motility & & \\
$0 \%$ & 49 & 8.2 \\
$1-59 \%$ & 157 & 26.1 \\
$60-80 \%$ & 303 & 50.5 \\
$>80 \%$ & 91 & 15.2 \\
\hline Sperm morphology & & \\
Abnormal forms & & \\
$\quad<10 \%$ & 0 & 0 \\
$10-20 \%$ & 163 & 27.2 \\
$21-40 \%$ & 397 & 66.2 \\
$41-60 \%$ & 35 & 5.8 \\
$\quad>60 \%$ & 5 & 0.8 \\
\hline
\end{tabular}


Table 5. Treatment protocol for the female spouse

\begin{tabular}{|c|c|c|c|c|}
\hline \multicolumn{2}{|c|}{ Treatment protocol } & \multirow{2}{*}{$\begin{array}{l}\text { Patients } \\
\text { treated }\end{array}$} & \multicolumn{2}{|c|}{ Successful ovulation } \\
\hline & & & patients & success, $\%$ \\
\hline \multirow[t]{5}{*}{ Medical } & Clomiphene citrate & 166 & 133 & 80.0 \\
\hline & Bromocriptine & 24 & 17 & 70.8 \\
\hline & Clomiphene citrate + bromocriptine & 67 & 32 & 47.8 \\
\hline & FSH and HCG & 13 & 9 & 69.2 \\
\hline & Thyroid hormone replacement therapy & 10 & - & - \\
\hline \multirow[t]{3}{*}{ Surgical } & Laparoscopic ovarian wedge resection & 1 & 1 & - \\
\hline & Laparoscopic ovarian drill & 15 & 12 & 80 \\
\hline & Adhesiolysis & 29 & - & - \\
\hline
\end{tabular}

these, $21(43 \%)$ had secretory and the rest had obstructive azoospermia. All the 21 men with secretory azoospermia had persistently high FSH and LH levels and low testosterone levels, while $12(42.9 \%)$ had Sertoli's cells only on fine needle testicular aspiration. In 157 men $(26.2 \%)$ there was asthenozoospermia defined as impaired sperm motility in which more than $40 \%$ of the spermatozoa in the semen were immotile. Forty-nine men (8.2\%) who had azoospermia expectedly showed no motility, and as expected in 49 men (8.2\%) with azoospermia, there was no motility, while 394 men (65.7\%) had normal sperm motility. Abnormal sperm forms of over $40 \%$ occurred in $6.8 \%$ of the men and the rest had normal sperm morphology.

As shown in table 5, there was successful induction in $80 \%$ of patients with clomiphene citrate, $71 \%$ with bromocriptine, $69 \%$ with FSH/HCG and $48 \%$ with a combination of clomiphene citrate and bromocriptine. Ovaluation occurred in $80 \%$ of patients that had ovarian cautery. Four $(30.8 \%)$ of the 13 patients who had induction of ovulation with gonadotropins had ovarian hyperstimulation syndrome. Of the 61 women with anovulatory regular cycles, 58 (95.1\%) achieved ovulation with clomiphene citrate.
The pregnancy rate was not computed at this stage for each of the modalities of induction, because of the difficulties of tracing the women once they became pregnant. Many of the women preferred antenatal care in polyclinics or private hospitals near to their homes, as soon as they became pregnant. During the study period, $164(27.4 \%)$ were referred for assisted reproductive technology. In the 21 couples where the husband had secretory azoospermia, with Sertoli's cells only, arrest of spermatogenesis at the primary or secondary spermatocyte stage, and hypergonadotropic hypogonadism, the poor prognosis was discussed with the couple truthfully and frankly.

\section{Discussion}

The present study has demonstrated that hypothalamic-pituitary-ovarian axis disorders with anovulation are the commonest single factor of infertility in Kuwait. Secondly, ovulation problems can be treated with a high degree of success. Tubal factor infertility is uncommon in Kuwait, unlike in many countries in Africa an South America and India, where environmental factors like infection 
leading to tubal infertility are common. Usually, the prognosis for tubal infertility, in terms of pregnancy, is poor [2, 4]. It has been reported that genital tuberculosis should be considered as a cause of infertility in India where prevalence is about $19 \%$ [8]. A recent report [9] has suggested that pelvic inflammatory disease is uncommon in Kuwait because of the strict religious and cultural practices that totally forbid premarital sexual indulgence and adolescent pregnancy, thus preventing consequent unsafe clandestine induced abortions and the burdensome sequelae of tubal blockage, chronic pelvic inflammatory disease and ectopic pregnancy.

Polycystic ovarian syndrome is the commonest endocrinopathy of infertility in $\mathrm{Ku}$ wait. Although the present study did not address the issue of obstetric outcome after induction of ovulation, it is known to be much better than with surgical treatment of tubal factor infertility [2, 4]. Clomiphene citrate remains the first line of therapy for ovulation induction in infertile patients with polycystic ovaries. Although ovaluation rates in excess of $80 \%$ are usually achieved, cumulative pregnancy rates with clomiphene therapy generally range between 40 and 50\% [10]. Currently, there is great interest in the genetic basis of polycystic ovarian syndrome. Genetic studies of family clusters and relatives of affective probands have shown a high incidence of affected relatives. A dominant mode of inheritance, rather than a recessive one, seems likely [11]. If such a hereditary pattern is unequivocally proved, there will be a role for genetic counselling as a preventable measure. Another important preventive measure is weight control. This is an important aspect of the management of obese and infertile women especially with polycystic ovarian syndrome. Such patients have been advised to embark on a weight reduction programme and maintain their BMI around 21 [12].

Causes and Treatment Options of Infertility in Kuwait
Ten percent of women in this study were 40-45 years old. The majority of the women got married a few years before presenting at the clinic. A parallel can be drawn with the situation in the United States of America and other industrialised countries, where many women delay childbearing to pursue a career and may reach their less fecund reproductive years by the time they decide to have a family [13]. In Kuwait, the delay in childbearing by these women is a result of late marriage from a cultural perspective in which premarital and out of wedlock pregnancy are serious taboos.

A male factor was the second most important factor for infertility among our patients. This has been the subject of many reports from our institution [14, 15]; as a result, a detailed analysis was not carried out in the present study. The role of antioxidants and zinc as an important trace element in the cupro-zinc superoxide dismutase with a beneficial effect in men with asthenozoospermia has been highlighted [16]. Excessive sweating during summer has been associated with zinc loss through the skin [17]. This is a common occurrence in Kuwait in the summer season, which could affect sperm function and cause infertility. The deficiency of natural antioxidants like vitamins $\mathrm{A}, \mathrm{C}$ and $\mathrm{E}$ in the diet could have adverse effects on gonadal development, spermatogenesis and sperm function [15]. More than $40 \%$ of our male patients admitted to smoking cigarettes. Although only $9.5 \%$ of the women admitted to smoking, for cultural reasons, this is obviously underestimated. Secondly, the effect of passive smoking cannot be ignored. Smoking is known to have a deleterious effect on the sperm [18] and possibly on ovarian function. There is little information in the literature on the role of environmental factors in the causation of anovulation in the human female. Oocytes are targets for chemical insults and can be injured by a variety of chemicals, drugs and heavy

Med Principles Pract 2000;9:131-138 137 
metals such as cadmium [19], which is one of the toxic components of cigarette smoke. The likely mechanism is by inhibition of oestrogen-synthesizing enzymes in the ovary or changes in the hypothalamic-pituitary-ovarian axis. This could also lead to changes in normal pubertal development in females [20]. Direct cadmium administration causes the induction of ovarian haemorrhage in some animals [21]. A public awareness campaign of the health hazards of cigarette smoking could therefore be an important preventive measure against infertility.
In conclusion, ovarian dysfunction and a male factor infertility are the dominant factors responsible for infertility in Kuwait. The prognosis after induction of ovulation is good. A significant proportion of infertility could be prevented through more aggressive application of standard public health measures.

\section{Acknowledgement}

Special thanks to all the doctors at the Maternity Hospital, who referred patients to the combined infertility clinic, and all the patients for their participation in the study.

\section{References}

1 Templeton A: Infertility-epidemiology, aetiology and effective management. Health Bull 1995;53:294298.

2 Chandra A, Stephen EH: Impaired fecundity in the United States 1982-1995. Fam Plann Perspect 1998;30:34-42.

3 Ericksen K, Brunnette T: Patterns and predictors of infertility among African women: A cross-national survey of twenty seven nations. Soc Sci Med 1996;42:209-220.

4 Leke RJ, Oduma JA, Bassol-Mayagoitia S, Bacha AM, Grigor KM: Regional and geographical variations in infertility: Effects of environmental, cultural and socioeconomic factors. Environ Health Perspect 1993; 101(suppl 2):73-80.

5 Li Y, Wang JL, Qian SZ, Gao ES, Tao JG: Infertility in a rural area of Jiangsu Province: An epidemiological survey. Int J Fertil 1990;35:347_ 349.

6 Webb S, Holman D: A survey of infertility, surgical sterility and associated reproductive disability in Perth, Western Australia, Aust J Public Health 1992;16:376-381.

7 Hamberger L, Janson PO: Global importance of infertility and its treatment: Role of fertility technologies. Int J Gynaecol Obstet 1997; 58:149-158.
8 John MZ, Kukkady A: Genital tuberculosis and infertility. Int $\mathrm{J}$ Gynaecol Obstet 1999;64:193-194.

9 Al-Motawa M, Omu AE, Ahmed NA, Kandil MM: Contribution of pelvic inflammatory disease to ectopic pregnancy: A clinical evaluation. Kuwait Med J 1999;31:128131.

10 Buyalos RP: Polycystic ovary syndrome: Pathophysiology and outcome with in vitro fertilization. Fertil Steril 1996;65:1-10.

11 Legro RS: The genetics of polycystic ovary syndrome. Am J Med 1995; 98:9-16S.

12 Eden JA, Place J, Carter GA, Jones J, Olagband-Zadeh J, Pawson ME: The diagnosis of polycystic ovaries in subfertile women. Br J Obstet Gynaecol 1989;96:809-815.

13 Wagner MG, Stephenson PA: Infertility in industrialized countries: Prevalence and prevention. Soz Präventivmed 1992;37:213-217.

14 Omu AE, Makhseed M, Mohammed AT, Munim RAA: Characteristics of men and women with circulating antisperm antibodies in a combined infertility clinic in $\mathrm{Ku}-$ wait. Arch Androl 1997;39:55-64.
15 Omu AE, Al-Othman S, Mohammad AS, Al-Kaluwby NM, Fernandes S: Antibiotic therapy for seminal infection: Effect of antioxidant activity and T-helper cytokines. J Reprod Med 1998;3:857864 .

16 Omu AE, Dashti H, Al-Othman S: Treatment of asthenozoospermia with zinc sulphate: Andrological, immunological and obstetric outcome. Eur J Obstet Gynecol Reprod Biol 1998;79:179-184.

17 Prasad AS: Zinc: Human nutrition and metabolic effects. Ann Intern Med 1970;73:631-636.

18 Omu AE, Dashti H, Mohammed AT, Mattappallil AB: Cigarette smoking causes impairment of spermatozoal quality: Andrological and biochemical evaluation. Med Principles Pract 1998;7:47-53.

19 Varga B, Paksy K: Toxic effects of cadmium on LHRH induced LH release and ovulation in rats. Reprod Toxicol 1991;5:199-203.

20 Mattison DR, Plowchalk DR, Meadows MJ, Juburi AZ, Gandy J, Malek A: Reproductive toxicity: Male and female reproductive systems as targets of chemical injury. Environ Med 1990;74:391-411.

21 Rehm S, Waalkes MP: Cadmium induced ovarian toxicity in hamster, mice and rats. Fundam Appl Toxicol 1988;10:635-647.

Omu/Al-Qattan/Ismail/Al-Taher/ Al-Busiri/Bandar 